\title{
A CASE REPORT OF RUPTURED VASA PREVIA
}

\author{
Amulya $\mathrm{L}^{1}$, Anitha $\mathrm{M}^{2}$, Syamala $\mathrm{O}^{3}$, Usha Rani ${ }^{4}$
}

\section{HOW TO CITE THIS ARTICLE:}

Amulya L, Anitha M, Syamala O, Usha Rani. "A case report of ruptured vasa previa". Journal of Evolution of Medical and Dental Sciences 2013; Vol2, Issue 36, September 9; Page: 6796-6799.

ABSTRACT: Vasa praevia occurs when the umbilical vessels cross the membranes of the lower uterine segment above the cervix, Unsupported by either the umbilical cord or placental tissue, these vessels are at risk of rupturing at the time of spontaneous or artificial membrane rupture, with subsequent bleeding of fetal origin. Here is a case report of ruptured vasa previa where patient presented to emergency with vaginal bleeding and spontaneous rupture of membranes a home. On examination bleeding was present with no uterine contractions and fetal bradycardia resulting in fetal mortality.

KEY WORDS: Vasa previa, antepartum haemorrhage, fetal mortality

INTRODUCTION: Vasa Previa is an uncommon variant of placental anatomy. The fetal vessels are unsupported by Wharton's jelly of the umbilical cord or placental mass and coursing within the membrane running between the cervix and fetal presenting part. It is one of the rare causes of antepartaum or intrapartum haemorrhage $(1,2) .50-60 \%$ of fetal mortality may cause by immediate fetal distress even if it is not ruptured, and because of the vessel compressed by the presenting part(3).Haemorrhage after the vessels are torn following spontaneous or artificial membrane rupture would result in a much higher fetal mortality rate ranging from 75 - 100 \%.(4).

CASE REPORT: A 33 year old women with Gravida 2, Para 1, live 1, at 38 weeks 3 days gestational age, antenatal course was uneventful and previous was normal delivery presented to the emergency at $3 \mathrm{pm}$ with vaginal bleeding and spontaneous rupture of membranes since $2 \mathrm{hrs}$ at home. She then came to emergency at $3 \mathrm{pm}$ with membrane rupture and vaginal bleeding. Initial examination revealed normal uterine tone without uterine contraction and vaginal bleeding. The fetus was in vertex presentation with mobile head. Foetal heart rate (FHR) was 70-80 beats / min (bpm.) by auscultation. Bedside ultrasound revealed a single viable fetus with scant amniotic fluid. The placenta lay posterior dipping into the lower uterine segment without retro placental blood clots. On per speculum examination the cervix was found to be closed with bleeding seen from the os. Concurrent FHR monitoring showed FHR baseline of $80 \mathrm{bpm}$. with markedly decrease variability with decelerations. With a probable diagnosis of vasa praevia, emergency caesarean section was performed. The pediatricians were informed of the diagnosis. A female baby weighing $3.2 \mathrm{Kg}$ was delivered at $3.24 \mathrm{pm}$ with Apgar 0 and 1 after resuscitation with volume replacement. The initial infant hematocrit was $46 \%$. On examination of the placenta, Velamentous cord insertion with partial rupture of a foetal vein with a clot at the ruptured site was observed (Figure 2). Postpartum period was uneventful and the Patient was discharged on the fourth day after delivery. The infant was transfused with a total of $60 \mathrm{ml}$ packed red cells and was on ventilator. The baby died on the 14th day of life. 


\section{CASE REPORT}

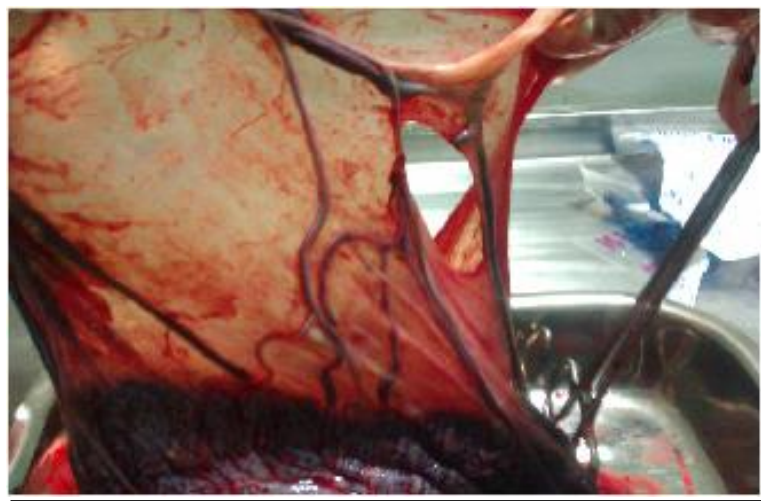

Figure 1: umbilical vessels crossing the

membranes

Microscopic examination of the aberrant vessel revealed a vessel - wall abnormality. The venous wall showed segmental thinning in the muscular layer (tunica media) with it very thin in some areas. The area of rupture showed acute inflammatory cells infiltrate, necrosis and fibrin depositions

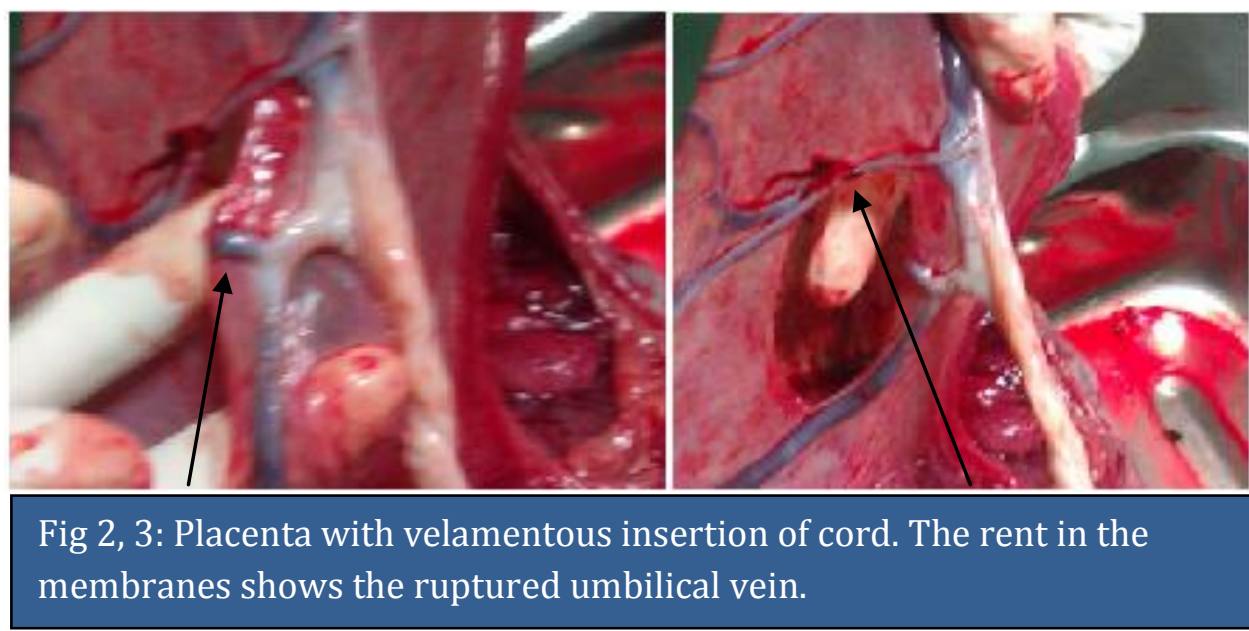

DISCUSSION: Vasa praevia is uncommon, with estimates of prevalence ranging from 1: 1250 - 1: 2700 (4) Nevertheless, its importance lies in the potential for serious maternal and fetal complications. The potential fetal risks associated with vasa praevia are sudden and catastrophic, and the maternal risks associated with emergency caesarean section under these circumstances are considerable. It is associated with a high fetal mortality rate (50 - $95 \%$ ) which can be attributed to rapid fetal exsanguinations resulting from the vessels tearing during labor. Risk factors for vasa praevia include placenta praevia, low lying placenta in the mid trimester, bilobed placenta, succenturiate lobe, Velamentous cord insertion detected at the time of routine morphology ultrasound, IVF pregnancy, multiple pregnancies. Identification of risk factors would include the use of colour Doppler at all routine ultrasound examinations of singleton pregnancies to identify the placental cord insertion (i.e. exclude velamentous insertion $(5,8,9)$. Antenatal clinical diagnosis is not possible in the absence of vaginal bleeding but diagnosis in labor is possible by palpation of 
pulsatile vessels in fore - bag. Targeted ultrasound examination of the lower uterine segment and cervical region using colour Doppler (with appropriate low flow settings ) in all pregnancies with risk factors for vasa praevia has been shown to be cost effective screening for vasa praevia(8,9,10). Current evidence confirms that antenatal diagnosis of vasa praevia is associated with improved out come. Routine screening with transvaginal ultrasound has not been shown to be cost effective $(5,6)$ If vasa praevia is diagnosed and confirmed, it is advised to admit at 28 to 32 weeks to a tertiary care center (7). Caesarean Section before labor at 35-37 weeks is advised and laser ablation therapy may be considered antenatally. While antenatal diagnosis optimizes outcome among women with known vasa praevia, undiagnosed cases will still occur, presenting in labour with variable decelerations and palpable vessels with intact membranes, and or intrapartum vaginal bleeding accompanied by acute fetal distress at the time of membrane rupture. Where fetal bleeding is suspected, plan for emergency caesarean section, resuscitation and management of the severely anaemic fetus should be made, including specialist paediatric support and availability of 0 negative blood for immediate transfusion.

CONCLUSIONS: Vasa previa is not a rare as we have traditionally thought to be. It is likely to be more common as multiple pregnancy, age and ART Increases. It is often antenatal detectable If well sensitized. Prenatal diagnosis makes a huge difference to the outcome (7).

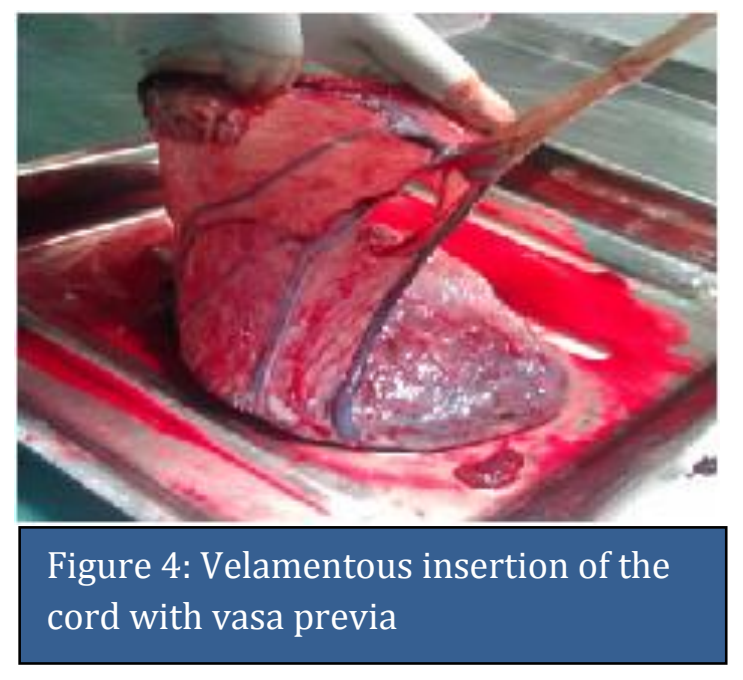

\section{REFERENCES:}

1. Quek SP, Tan KL. Vasa previa. Aust NZ J Obstet Gynecol 1972; 12:206-9.

2. Kouyoumdjian A. Velamentous insertion of umbilical cord. Obstet Gynecol 1980; 56:737-42.

3. Fung TY, Lau TK. Poor perinatal outcome associated with Vasa Previa: is it preventable? A report of three cases and review of the literature. Ultrasound Obstet Gynecol 1998; 12:430-3.

4. Pent D. Vasa Previa. Am J Obstet Gynecol 1979; 15 151-5.

5. SOGC Clinical Practice Guideline No 231, August 2009. Guidelines for the management of vasa previa.

6. The cost-effectiveness of targeted or universal screening for vasa praevia at 18-20 weeks of gestation in Ontario. BJOG 2010; 117 (9): 1108-18. Epub 2010 Jun 18. 
7. Prenatal diagnosis and management of vasa previa: a 6-year review. J Obstet Gynaecol Res 2011; 37 (10): 1391-6.

8. An accurate diagnosis of vasa previa with transvaginal color Doppler Ultrasonography. Am J Obstet Gynecol 1994; 171:265-7.

9. Nomiyama M, Toyota Y, Kawano H. Antenatal diagnosis of Velamentous umbilical cord insertion and Vasa Previa with color Doppler imaging. Ultrasound Obstet Gynecol 1998; 12:426-9.

10. Oyelese KO, Schwarzler P, Coates S, Sanusi A, Hamid R, Campbell S. A strategy for reducing the mortality rate from Vasa Previa using transvaginal sonography with color Doppler. Ultrasound Obstet Gynecol 1998; 12:434-8.

\section{AUTHORS:}

1. Amulya L.

2. Anitha M.

3. Syamala 0 .

4. Usha Rani

\section{PARTICULARS OF CONTRIBUTORS:}

1. Post Graduate, Department of Obstetrics and Gynaecology, Sri Ramachandra Medical College, Porur, Chennai, Tamilnadu, India.

2. Assistant Professor, Department of Obstetrics and Gynaecology, Sri Ramachandra Medical College, Porur, Chennai, Tamilnadu, India.

3. Associate Professor, Department of Obstetrics and Gynaecology, Sri Ramachandra Medical College, Porur, Chennai, Tamilnadu, India
4. Professor, Department of Obstetrics and Gynaecology, Sri Ramachandra Medical College, Porur, Chennai, Tamilnadu, India.

\section{NAME ADDRESS EMAIL ID OF THE CORRESPONDING AUTHOR:}

Dr. Amulya L,

Final Year Post Graduate,

Department of Obstetrics and Gynaecology,

Sri Ramachandra Medical College,

Porur, Chennai.

Email - lagadapati.amu@gmail.com

Date of Submission: 17/08/2013.

Date of Peer Review: 18/08/2013.

Date of Acceptance: 29/08/2013.

Date of Publishing: 03/09/2013 